\title{
How to Feed the World: The Need to Change Focus and to Break Paradigms in Animal Origin Nutrients Production
}

\author{
Marcos Franke Pinto* \\ Department of Veterinary Medicine, Brazil \\ *Corresponding author: Marcos Franke Pinto, Department of Veterinary Medicine, Araçatuba/SP, Brazil

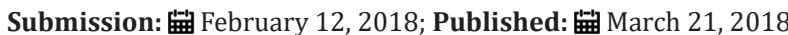

\section{Opinion}

Producing enough food to properly nourish the world population without crippling the planetary ecosystem is a great challenge. In livestock production, many efforts are being made in various science and technology areas involved like genetics, nutrition, ambience and management, even raising questioning about the ethical limits of technological development considering the inter-species relation. But one rarely approached aspect is the inefficiency of the vegetal nutrients to animal origin food conversion process. The handling of the imbalance caused by human overpopulation on the planet and its food necessities essentially involves making the dynamics of all the variables involved in the process of producing animal origin nutrients as transparent as possible.

Taking the example of broiler chicken meat production, making simple calculations based on expected performance indexes for commercial fast-growing broiler strains, it can be seen that the meat obtained from the breeding process provides about four times less protein and six times less energy than the food consumed by birds. Additionally, the breeding process demands water, oxygen, energy, manpower, area and facilities, and produces C02, methane, urea, ammonia and other solid and liquid pollutants. It is urgent to admit this reality and make it clear and available, with scientific criteria.

The nutritional variables consumed and produced in the process must be disclosed in order to develop mathematical models that make the dynamics and the interrelation of these variables transparent throughout the process of bird breeding and its transformation into animal nutrients.

Once this reality is widely known, disseminated and accepted, there will be two paths to reduce the imbalance of this equation: decrease the inputs and increase the outputs of the process. Genetic development of broiler chickens has been based on producing strains able to convert, faster and more efficiently, high-quality ingredients-especially corn and soybean-into muscle tissue. The issue in question is that most of the grains fed to the livestock could be destined for human nutrition. An alternative would be to change the focus of future studies on genetic improvement for selecting birds that may consume alternative nutrient sources, as agroindustrial by-products and crop residues.

Another aspect worth mentioning is the accuracy development in feed formulation, avoiding surpluses and waste of nutrients. The use of enzymes in the ration may be considered in order to increase nutrient absorption and reduce the presence of pollutants in the feces. As for the process outputs, some points such as the water reuse and a more rational management of excreta and litter to reduce environmental impact, mainly the greenhouse gases emission, require research efforts to be improved.

A key point that needs to be widely studied is the development of the birds' corporal tissues throughout the rearing period. It is well known that the acceleration of birds' weight gain is not linear. There is an inflection point, from which the energy and nutrients needed to maintain preformed body mass impairs the production of new tissues. The accurate determination of the best slaughter age, taking into account productivity and sustainability, can be decisive in the process optimization.

It seems likely that slaughtering the birds at the exact point of the muscle mass development deceleration may have a relevant effect on the efficiency of chicken meat production. In summary, to allow the clear picturing of the inputs and outputs dynamic throughout the process of poultry meat production, not considering commercial interests, is crucial to address the challenge of feeding the world without destroying the planet. And it is clear that, in a food shortage situation, using grains and other high nutritional value ingredients to produce meat is not part of the solution. 
(c) (i)

Creative Commons Attribution 4.0 International License

For possible submissions Click Here

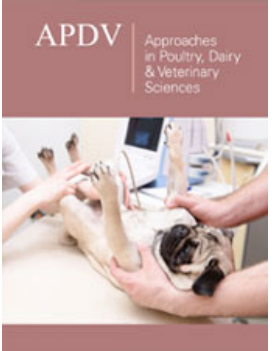

Approaches in Poultry, Dairy \& Veterinary Sciences

\section{Benefits of Publishing with us}

- High-level peer review and editorial services

- Freely accessible online immediately upon publication

- Authors retain the copyright to their work

- Licensing it under a Creative Commons license

- Visibility through different online platforms 